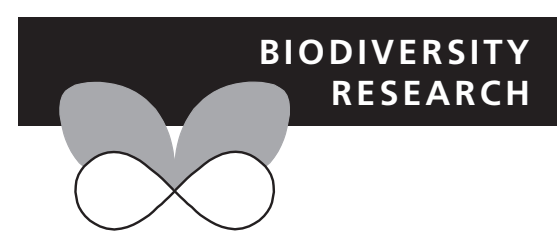

\title{
Region-specific patterns and drivers of macroscale forest plant invasions
}

\author{
Basil V. Iannone $\mathrm{III}^{1}$, Christopher M. Oswalt ${ }^{2}$, Andrew M. Liebhold ${ }^{3}$, \\ Qinfeng Guo ${ }^{4}$, Kevin M. Potter ${ }^{5}$, Gabriela C. Nunez-Mir ${ }^{1}$, Sonja N. \\ Oswalt ${ }^{2}$, Bryan C. Pijanowski ${ }^{1}$ and Songlin $\mathrm{Fei}^{1 *}$
}

${ }^{1}$ Department of Forestry and Natural Resources, Purdue University, West Lafayette, IN, USA, ${ }^{2}$ USDA Forest Service Southern Research Station, Knoxville, TN, USA, ${ }^{3}$ USDA Forest Service Northern Research Station, Morgantown, WV, USA, ${ }^{4}$ USDA Forest Service Southern Research Station, Asheville, NC, USA, ${ }^{5}$ Department of Forestry and Environmental Resources, North Carolina State University, Research Triangle Park, NC, USA

${ }^{\star}$ Correspondence: Songlin Fei, Department of Forestry and Natural Resources, Purdue University, 715 W. State Street, West Lafayette, IN, USA. E-mail: sfei@purdue.edu

\begin{abstract}
Aim Stronger inferences about biological invasions may be obtained when accounting for multiple invasion measures and the spatial heterogeneity occurring across large geographic areas. We pursued this enquiry by utilizing a multimeasure, multiregional framework to investigate forest plant invasions at a subcontinental scale.
\end{abstract}

Location United States of America (USA).

Methods Using empirical data from a national survey of USA forests, we compiled and mapped invasion richness (number of invasive species) and invasion prevalence (percentage of plots invaded) for 2524 counties. We then modelled each of these invasion measures as functions of 22 factors reflective of propagule pressure and/or habitat invasibility for eastern and western forests separately using simultaneous autoregressive spatial error models.

Results Eastern forests had higher mean invasion richness (6.1) and prevalence (48\%) than western forests (3.2 and 10\%, respectively). Spatial patterns of invasion richness and prevalence differed, especially in the West. Propagule pressure factors were always positively associated with both invasion measures. Factors associated with human legacy were nearly six times more strongly associated with western than eastern invasions. Unlike propagule pressure factors, habitat invasibility factors shared inconsistent associations with invasion measures.

Main conclusions The weaker associations between human legacy and invasions in the heavily invaded East, compared to the less-invaded West, suggest a declining effect of propagule pressure over time with increasing invasion intensity. The importance of propagule pressure in less-invaded western forests suggests that spatial variability in propagule inputs, coupled with lags between establishment and commonness, drives the spatial differences between invasion richness and prevalence during early invasion stages. Meanwhile, declining spatial disagreement between invasion measures and the relative unimportance of propagule pressure, in heavily invaded eastern forests, suggest that speciesspecific variation in response to habitat invasibility drives spatial differences between invasion measures during later invasion stages. These insights further illustrate the importance of spatial heterogeneity in invasive plant management and policy at macroscales.

\section{Keywords}

Biological invasions, Forest Inventory and Analysis Program, habitat invasibility, macrosystems, propagule pressure, spatial autocorrelation, spatial heterogeneity. 


\section{INTRODUCTION}

Biological invasions are a major component of global change (Vitousek et al., 1997; Ricciardi, 2007), resulting in significant impacts (Simberloff et al., 2013; Fei et al., 2014). The fact that global-level processes drive invasions and that many species become invasive illustrate the need to study invasions using a macroecological framework, that is across both large geographic areas and a wide range of species and taxa (sensu Brown, 1999). Conducting such investigations can help to detect robust patterns and processes that transcend taxonomic and geographic boundaries (Brown, 1999), and help to control for potential biases occurring from studying too few species or spatial scales that are too small (Hulme et al., 2013). Despite the vast number of smaller-scale investigations on biological invasions, these studies cannot provide comprehensive insight into the complexities of invasions at macroscales (Pauchard \& Shea, 2006), as data required to do so need to be collected across multiple geographic scales (Araújo \& Rozenfeld, 2014).

Despite the proven utility of a macroecological framework for investigating invasions, certain key advancements to this framework may improve our understanding of invasion dynamics. The first is accounting for the fact that invasions can be measured in multiple ways. Obtaining multiple measures of invasion, however, is often challenging, especially at the continental to subcontinental scales. Data limitations unfortunately lead to a reliance on invasive species richness as the only measure to interpret macroscale invasion patterns (e.g. Guo et al., 2012; Liebhold et al., 2013), despite the potentially greater utility of other measures. For instance, measures such as invasion prevalence or dominance may better reflect invader impacts, making them more relevant to policy and management (Guo \& Symstad, 2008; Hillebrand et al., 2008). Additionally, as illustrated both theoretically (Guo \& Symstad, 2008; Catford et al., 2012) and empirically from local to subcontinental scales (Kennedy et al., 2002; Stohlgren et al., 2003), deeper insights can be gained by quantifying and analysing multiple invasion measures [e.g. devising better management practices by detecting varying effects of the same factor on different invader life stages (Iannone \& Galatowitsch, 2008; Iannone et al., 2013)].

Another key advancement to improve our understanding of invasions can come from accounting for the considerable spatial heterogeneity that occurs across large regions [e.g. the ecoregions of the United States of America (USA) (Cleland et al., 2007)]. This heterogeneity likely affects both the sizes and directions of the associations between invasion drivers and patterns. At the global scale, spatial heterogeneity possibly contributes to the considerable variability observed among regions in the sizes of associations between propagule pressure and invasion patterns (Lin et al., 2011). At the regional scale, spatial heterogeneity may cause changes in the directionality of associations between native and exotic plant species richness (Shea \& Chesson, 2002).
Finally, our understanding of invasions that has emerged from analyses of large datasets (Richardson, 2004) can be improved via higher data quality and resolution. Many studies rely on data compiled from anecdotal records of species presence/absence within a given geographic region (e.g. Stohlgren et al., 2006; Gavier-Pizarro et al., 2010; Pyšek et al., 2010), probably due to the lack of access to systematic empirical field data. For this same reason, many of these investigations included all exotic species, not only those known to be invasive (e.g. Stohlgren et al., 2006; Pyšek et al., 2010; Guo et al., 2012), and were conducted across most, if not all, terrestrial systems within a given geographic area (e.g. Stohlgren et al., 2006; Gavier-Pizarro et al., 2010; Pyšek et al., 2010). Utilizing empirically collected data focused on species known to cause socioeconomic or ecological threats [i.e. to be invasive within the context of management and policy (sensu Ries et al., 2004; Mehrhoff et al., 2014)] in a specific system may facilitate better targeted management and policy recommendations.

Here, we report the findings of an investigation aimed at determining whether our understanding of biological invasions at macroscales can be improved by (1) considering more than one invasion measure, (2) accounting for the spatial heterogeneity inherent to large study regions and (3) using high-resolution datasets. To do so, we modelled two measures of invasion (invasion richness and invasion prevalence, defined below) across two ecologically distinct regions of the USA (eastern and western forests) as functions of factors related to propagule pressure and habitat invasibility - two widely recognized components of invasion at macroscales, particularly in forests (Catford et al., 2009; GavierPizarro et al., 2010; Pyšek et al., 2010; Guo et al., 2012; Liebhold et al., 2013). Our specific objectives were to (1) identify spatial patterns of forest plant invasions and (2) assess the extent to which accounting for multiple invasion measures and spatial heterogeneity affects these spatial patterns and determines the factors to which these spatial patterns are most strongly associated. Our focus on forests is of practical importance as these globally abundant systems provide a wide range of services linked to human well-being (Gonzalez et al., 2005) that are potentially threatened by numerous invasive plant species (Martin et al., 2009; Pejchar \& Mooney, 2009). This improved understanding will aid the development of better invasion management and policy.

\section{METHODS}

\section{Depicting geographic patterns}

To determine spatial patterns of forest plant invasions (objective 1), we mapped invasion richness and invasion prevalence (defined below) for 2524 counties within the contiguous 48 states of the USA. These data were collected as part of the United States Forest Service's Forest Inventory and Analysis Program (FIA) (Bechtold \& Patterson, 2005), 
specifically for the 2012 iteration of this dataset (Oswalt et al., 2015). FIA monitors forests at an approximate intensity of one 0.40 -ha plot per 2428 ha of forest, resulting in about 120,000 plots for our study region. FIA defines forests as areas at least $37 \mathrm{~m}$ wide and 0.40 ha in size not slated for non-forest use that are, or were, covered at least $10 \%$ by trees of any size (Bechtold \& Patterson, 2005). We used counties as our sample unit because that was the resolution at which plant invasions and some explanatory variables (described below) were quantified.

FIA defines 'invasive plants' in accordance with USA Executive Order 13112 as exotic plant species of any growth form likely to cause economic or environmental harm (Ries et al., 2004). The number of plots, and the specific species, monitored varied among the FIA regions depicted in Fig. S1, Supporting Information. Nonetheless, there was considerable overlap in the species monitored between adjoining FIA regions (Table S2), thus accounting for cross-regional invasions. Concerns regarding variability in species monitored were further alleviated by investigating non-species-specific invasion measures. Variability in sampling efforts was accounted for in our statistical analysis (described below).

For this study, invasion richness is defined as the number of invasive plant species detected across all monitored FIA plots in a given county, thus estimating the number of invasive species that have established in that county's forests. Invasion prevalence is defined as the percentage of monitored FIA plots in a given county having at least one invasive plant present, thus estimating invasion commonness. We did not have reliable estimates for invasion richness in 27 western counties and therefore excluded these counties from our analysis.

\section{Determining variability in factors associated with invasion patterns}

To determine the extent to which different invasion measures and spatial heterogeneity affect factors most associated with invasion patterns (objective 2), we modelled each invasion measure separately for eastern and western forests as a function of 22 variables reflecting propagule pressure (hereafter propagule terms) and/or habitat characteristics that affect the ability of propagules to establish (hereafter invasibility terms). We were primarily interested in how final models for the two invasion measures and for the two halves of the USA differed, and not in the effects of any specific explanatory variable per se. Therefore, we investigated variables already determined to be associated with macroscale invasion patterns (Guo et al., 2012; Liebhold et al., 2013). Propagule and invasibility terms, and a brief explanation of their utility, are listed in Table 1. Further explanation of variables, including data sources and necessary pre-calculations, are provided in Appendix S3.

The East-West subdivision used was a justifiable first step for assessing the effects of spatial heterogeneity. Forests in these regions are well known to differ in climate, vegetation, topography, geology and soils (Cleland et al., 1997; McNab et al., 2007), suggesting they also differ in invasion drivers, and in the directionalities and strengths of driver effects. These forests are also isolated from one another and have very different histories of European settlement, leading to different ownership patterns [a much higher proportion of western forests are publicly owned (Smith et al., 2002)]. Finally, western counties tend to be considerably larger than eastern counties (mean $\pm \mathrm{SD}=7400 \pm 6900$ vs. $1600 \pm 1100 \mathrm{~km}^{2}$, respectively).

Our analysis of invasion richness had to address variable sampling efforts among both counties and FIA regions since this variability affects estimates of species richness (Patiño et al., 2014). Therefore, we included the proportion of forested area and county area as explanatory variables in our statistical models. As FIA plots occur at fixed spatial increments (Bechtold \& Patterson, 2005), these variables relate to sampling effort. Dividing invasion richness by area of forest monitored would have been insufficient, as this approach assumes rates of species accumulation to be linearly related to sampling effort, homogeneous across large areas and unaffected by invader presence, all of which are unlikely (Powell et al., 2013; Patiño et al., 2014). We did not conduct separate analyses for each FIA region, as ecological regions overlap FIA regional boundaries (Cleland et al., 2007). Nor did we incorporate FIA region into our statistical models, as this variable was redundant with others providing mechanistic understanding, including mean annual temperature, precipitation, elevation and years since incorporation into the USA (Goodman-Kruskal's $G=0.80$ to 0.94 ). These potential sources of bias did not affect invasion prevalence, as this measure inherently standardizes for both sampling effort and the number of species monitored.

Ecological inferences at the macroscale often reflect no more than the explanatory variables chosen, or available, to investigate (Guo et al., 2012). Rejmánek (2003) illustrated how this limitation can raise concerns when variables are collinear. By adding terms related to human demography to statistical models, he produced results contradicting Stohlgren et al. (2003)'s finding of a positive relationship between native and exotic plant diversity. To avoid similar complications associated with collinearity (Legendre \& Legendre, 2012), we employed a multitiered modelling approach.

First, we selected propagule and invasibility terms having limited collinearity $(|r|<0.75)$. Inspection of variance inflation factors for preliminary linear models also revealed little evidence of complications due to collinearity (Legendre \& Legendre, 2012). Next, we modelled each invasion measure as a function of propagule and invasibility terms separately, eliminating between-group collinearity. Backwards selection was used to find the most parsimonious models. We then combined the terms of the two reduced models, again screened for collinearity among combined terms and repeated backwards selection. When collinearity occurred, we removed one of the covarying terms. For backward selection, 


\section{B. V. lannone III et al.}

Table 1 List of propagule and invasibility terms investigated in relation to invasion richness and prevalence. Included is their abbreviations, units and definitions (when needed), and a brief explanation of what aspect of propagule pressure and/or habitat invasibility each reflect. Explanations, while illustrating the term's utility, are not exhaustive, as other explanations for use likely exist. Also, explanations may not be mutually exclusive. See Appendix S3 for further details on the inclusion of each variable, and the methods in which these data were compiled. Note that proportion of forested area is considered both a propagule and an invasibility term.

Propagule terms (Abbreviation; Unit)
Proportion of forested area (PropFor)
Population density in 1900 (Pop1900; individuals $\mathrm{km}^{-2}$ )
Population density in 2010 (Pop2010; individuals $\mathrm{km}^{-2}$ )
Years since incorporation into the USA (YrIncorp)
Road density (RdDen; km of road km ${ }^{-2}$ )
Per capita income in 2012 (PcInc2012; \$ individual-year ${ }^{-1}$ )
Distance to port (DistPort; km)

Reflective of

Internal sources of propagules and sampling effort

Historical human-induced propagule inputs

Recent human-induced propagule inputs

Length of time that county has experienced human-induced propagule inputs Within- and cross-county propagule movement

Recent magnitude of economic activity and thus recent propagule pressure Propagule pressure from international sources. Distance to the closest of ten ports having the greatest import tonnage

\begin{tabular}{|c|c|}
\hline Invasibility terms (Abbreviation; Unit) & Reflective of \\
\hline County Area (Area; $\left.\mathrm{km}^{2}\right)$ & Habitat availability, including those other than forests, and sampling effort \\
\hline Proportion of forested area (PropFor) & Habitat availability and sampling effort \\
\hline Proportion of developed area (PropDev) & Habitat disturbance and land use patterns \\
\hline Proportion of agricultural area (PropAg) & Habitat disturbance and land use patterns \\
\hline $\begin{array}{l}\text { Mean native tree live biomass (NatBiom; } \\
{\left[\text { Eng. Tons acre }{ }^{-1} \text { ] FIA } \text { plot }^{-1} \text { ) }\right.}\end{array}$ & Biotic resistance \\
\hline $\begin{array}{l}\text { Mean native tree species richness } \\
\left(\text { NatSpRich; Species FIA plot }{ }^{-1}\right)\end{array}$ & Biotic resistance \\
\hline $\begin{array}{l}\text { Mean native tree phylogenetic species variability } \\
\left(\text { PSV; PSV FIA } \text { plot }^{-1}\right)^{*}\end{array}$ & Biotic resistance \\
\hline $\begin{array}{l}\text { Coefficient of variation (CV) native tree live biomass } \\
\text { (cvNatBiom) }\end{array}$ & Variability exhibited across forests within each county in potential biotic resistance \\
\hline $\mathrm{CV}$ native tree species richness (cvNatSpRich) & Variability exhibited across forests within each county in potential biotic resistance \\
\hline CV native tree phylogenetic species variability (cvPSV) & Variability exhibited across forests within each county in potential biotic resistance \\
\hline Mean natural forest fragmentation (NatFrag; \%) & Landscape-scale patterns affecting environmental conditions and movement \\
\hline Mean human-caused forest fragmentation (HumFrag; \%) & $\begin{array}{l}\text { Habitat disturbance and landscape-scale patterns affecting environmental } \\
\text { conditions and movement }\end{array}$ \\
\hline Annual precipitation (Precip; mm) & Climatic conditions \\
\hline Mean annual temperature $\left(\mathrm{Temp} ;{ }^{\circ} \mathrm{C}\right)$ & Climatic conditions \\
\hline Mean elevation (Elev; m) & Climatic conditions \\
\hline
\end{tabular}

*We used phylogenetic species variability to estimate phylogenetic diversity as it tends to be statistically independent of species richness; values range from 0 to 1 with species becoming less related with increasing values (Helmus et al., 2007).

we iteratively removed the term having highest $P$ value until doing so increased the model's AIC score by more than 2 (Burnham \& Anderson, 2002) or until all terms had $P$ values less than 0.05 .

To avoid overly complex models due to spatial autocorrelation-induced distorted estimates of statistical significance (Diniz-Filho et al., 2008; Legendre \& Legendre, 2012), we used simultaneous autoregressive error models $\left(\mathrm{SAR}_{\mathrm{err}}\right)$ to analyse the relationships between invasion measures and propagule and invisibility terms. $\mathrm{SAR}_{\text {err }}$ models can produce robust estimates regardless of spatial autocorrelation occurring within the response variable, explanatory variables or model error term (Kissling \& Carl, 2008), all of which are possible given the large amount of variables investigated (2 response; 22 explanatory). We assumed a variance-stabilizing spatial link matrix (Tiefelsdorf et al., 1999), and a 1-degree neighbourhood distance, selected upon inspection of correlograms and AIC scores from preliminary statistical models. We used pseudo $R^{2}$ values [squared Pearson correlations between fitted and actual response values (Kissling \& Carl, 2008)] and standardized model residuals ( $z$-scores) to assess model goodness-of-fit.

Statistical analyses were conducted using $\mathrm{R}$ version 3.0.1 ( $\mathrm{R}$ Core Team, 2013) with $\mathrm{SAR}_{\text {err }}$ models being constructed using the 'spdep' package (Bivand, 2014). Prior to analyses, highly skewed variables were transformed as described in Table S4. Transformations sometimes differed between eastern and western models. Nevertheless, we standardized all variables $[(x-\operatorname{mean}[x]) / \mathrm{SD}(x)]$ to facilitate the determination of the relative contribution of explanatory variables to each model and to facilitate cross-model comparisons (Schielzeth, 2010). 


\section{RESULTS}

\section{Invasion spatial patterns}

Eastern forests were more invaded than western forests, yet spatial patterns for the two invasion measures did not always coincide (Fig. 1). The mean \pm SE invasion richness per county was $6.1 \pm 0.1$ in the East and $3.2 \pm 0.2$ in the West. Eighty-one per cent of counties had three or more invasive plant species in the East, compared to only $45 \%$ in the West ( $\max$ invasion richness $=19$ and 14 for East and West, respectively). Similarly, mean \pm SE invasive prevalence was $48 \pm 1 \%$ in the East and only $10 \pm 1 \%$ in the West. Nearly half $(48 \%)$ of the counties in the East, compared to only $2 \%$ of those in the West, had invasion prevalence values greater than $50 \%$.

In the East, invasion patterns were spatially heterogeneous. Forests having the highest invasion richness were in the south-east and east, while those having the lowest were in the north, the Great Plains, and along the Mississippi River (Fig. 1a). Forests having the highest invasion prevalence were within the agriculturally dominated Midwest, metropolitan areas and the south-east, while those having the lowest were in the north, along the Atlantic and Gulf of Mexico coasts, and in northern Florida (Fig. 1b). Smaller pockets of low-invasion richness and prevalence were also embedded within larger, more heavily invaded areas (Fig. 1a,b).

In the West, patterns of invasion richness were also heterogeneous. Forests having the greatest invasion richness occurred along the Pacific coast, and in parts of Colorado, Idaho and Montana (Fig. 1a). In contrast, patterns of invasion prevalence were more homogeneous, remaining low throughout most of the region (Fig. 1b).

\section{Invasion drivers}

Our analyses suggest that both propagule pressure and habitat invasibility contribute to macroscale patterns of forest
Figure 1 Geographic patterns of forest plant invasions for (a) invasion richness and (b) invasion prevalence in the contiguous 48 states of the USA. Counties are masked by forest area (Appendix S3). Counties having outlines are those in which we did not have reliable estimates for invasion richness. Note differences between East and West in invasions, as well as between spatial patterns for invasion richness and prevalence.

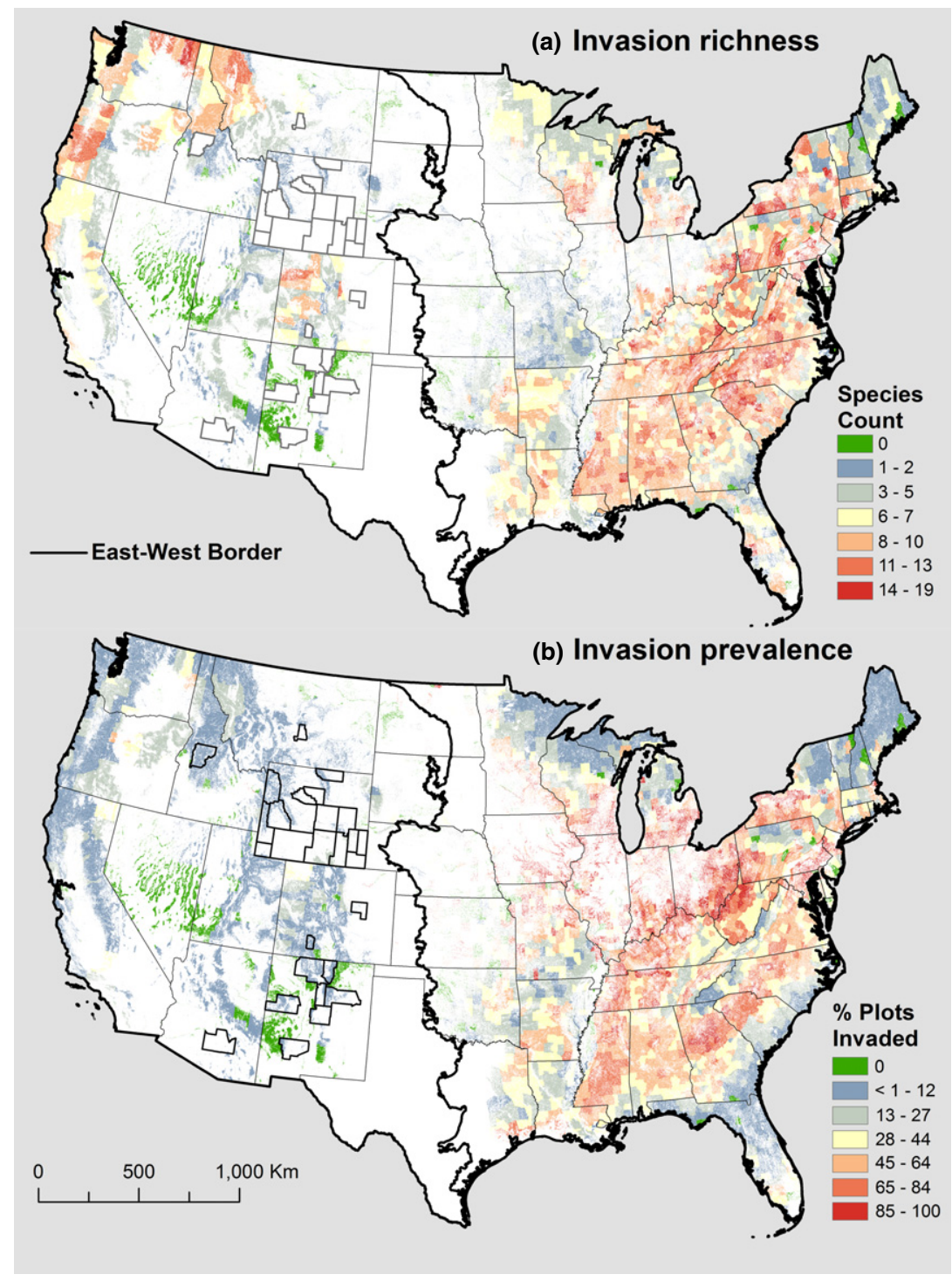


plant invasions, but the extent to which they do varies considerably between invasion measures, and between regions (Table 2; Figs. S5 and S6). Earlier stages of the multitiered analysis yielded similar conclusions to those of models containing both propagule and invasibility terms (Appendix S7), for which we report here. The amount of variability explained by our final models differed between the two invasion measures considerably less in eastern than western forests (pseudo $R^{2}=0.57$ to 0.59 and 0.42 to 0.69 , respectively; Table 2). Less than $2 \%$ of model residuals had $z$-scores greater than 1.96 or less than -1.96 (i.e. had $P$ values $\leq$ $0.05)$, with most $(81 \%$ to $95 \%)$ ranging between -1 and 1 (i.e. having $P$ values $\geq 0.32$; Fig. S8), thus revealing the overall reliability of our statistical models.

\section{Patterns associated with propagule pressure}

Despite exhibiting distinct spatial patterns, both invasion measures shared similar associations among propagule terms in both eastern and western forests. In the East, population density in 2010 and 1900 were both positively related to invasion richness and prevalence (Table 2; Fig. 2). In the West, population density in 2010 , distance to the nearest port and years since incorporation into the USA were each positively related to both invasion measures (Table 2b; Fig. 2).

The degree of associations for a given propagule term, however, often varied considerably between invasion measures. In the East, population density in 2010 and in 1900 were both nearly two times more strongly associated with invasion richness than prevalence (Table $2 \mathrm{a}$ ). In the West, years since incorporation into the USA and distance to the nearest port were two times and $42 \%$, respectively, more strongly associated with invasion prevalence than richness (Table 2b).

Final statistical models also suggest that propagule pressure plays a lesser role in driving invasion patterns in eastern than western forests. Eastern models contained up to three times as many invasibility terms as propagule terms, and the propagule terms in these models had associations 14 to $35 \%$ weaker than the next stronger-associated invasibility term (Table 2a). In contrast, western models had equal, or nearly equal, amounts of propagule and invasibility terms, and the association sizes for propagule terms were often greater than, or comparable to, those of invasibility terms (Table $2 \mathrm{~b}$ ). The one propagule term occurring in all models regardless of region was population density in 2010 . This term was, however, two times more strongly associated with invasion prevalence in the West than in the East (Table $2 b$ ).

The proportion of forested area, which we defined as both a propagule and invasibility term (Table 1), was positively associated with invasion richness and negatively associated with invasion prevalence in the East, but was positively associated with both measures in the West (Table 2; Fig. 2). Per capita income in 2012 was not associated with either invasion measure $(P=0.60$ to $0.99 ; \Delta \mathrm{AIC} \leq 0)$, and road density was not included in final models (Appendix S7).
Table 2 Relative associations of propagule $(\mathrm{P})$ and invasibility (I) terms in final reduced SAR err models for (a) eastern and (b) western forests. Detailed results of preceding steps in the multitiered approach can be found in Table S7.1 of Appendix S7. Proportion developed (PropDev) was dropped from analyses as it was redundant with population density in $2010(r=0.90$ in East and 0.88 in West) and the latter term better met the distributional assumptions of SAR err models. See Table 1 for definition of abbreviations. Note that elevation had a $P=0.053$ in model preceding the final model for invasion richness in western forests. Removing it from the model, however, caused no change in the interpretation of other terms. Because of this and its extremely weak effect size $(-0.085 \pm 0.044)$, we treated the more parsimonious model as the final model.

(a) Eastern forests

Invasion richness $(N=2104)$

\begin{tabular}{lrllr}
\hline $\begin{array}{l}\text { Model term } \\
\text { (term type) }\end{array}$ & Estimate \pm SE & & $\begin{array}{l}\text { Model term } \\
\text { (term type) }\end{array}$ & Estimate \pm SE \\
\hline PropFor (P, I) & $0.43 \pm 0.04$ & HumFrag (I) & $0.22 \pm 0.04$ \\
Area (I) & $0.33 \pm 0.02$ & & PropFor (P, I) & $-0.16 \pm 0.04$ \\
Temp (I) & $0.26 \pm 0.05$ & & Temp (I) & $-0.16 \pm 0.05$ \\
HumFrag (I) & $0.26 \pm 0.04$ & Elev (I) & $-0.14 \pm 0.05$ \\
Precip (I) & $-0.18 \pm 0.05$ & NatFrag (I) & $-0.13 \pm 0.04$ \\
Pop2010 (P) & $0.15 \pm 0.02$ & Pop1900 (P) & $0.08 \pm 0.02$ \\
NatFrag (I) & $-0.13 \pm 0.03$ & Pop2010 (P) & $0.07 \pm 0.02$ \\
Pop1900 (P) & $0.12 \pm 0.02$ & Area (I) & $-0.06 \pm 0.02$ \\
& & PSV (I) & $-0.05 \pm 0.02 *$ \\
pseudo $R^{2}=0.59$ & & pseudo $R^{2}=0.57$ \\
\hline
\end{tabular}

(b) Western forests

Invasion richness $(N=393)$

\begin{tabular}{lclll}
\hline $\begin{array}{l}\text { Model term } \\
\text { (term type) }\end{array}$ & Estimate \pm SE & $\begin{array}{l}\text { Model term } \\
\text { (term type) }\end{array}$ & Estimate \pm SE \\
\hline PropFor (P, I) & $0.65 \pm 0.05$ & DistPort (P) & $0.60 \pm 0.08$ \\
DistPort (P) & $0.42 \pm 0.07$ & YrIncorp (P) & $0.49 \pm 0.06$ \\
Area (I) & $0.32 \pm 0.04$ & Pop2010 (P) & $0.22 \pm 0.06$ \\
Temp (I) & $0.27 \pm 0.07$ & NatFrag (I) & $0.17 \pm 0.05$ \\
YrIncorp (P) & $0.23 \pm 0.05$ & Temp (I) & $0.16 \pm 0.08^{*}$ \\
NatBiom (I) & $0.16 \pm 0.07^{*}$ & Area (I) & $0.15 \pm 0.05$ \\
Pop2010 (P) & $0.15 \pm 0.05$ & PropFor (P, I) & $0.14 \pm 0.05$ \\
HumFrag (I) & $0.12 \pm 0.05^{*}$ & & \\
NatSpRich (I) & $-0.12 \pm 0.06^{*}$ & & \\
pseudo $R^{2}=0.69$ & & pseudo $R^{2}=0.42$ \\
\hline
\end{tabular}

${ }^{*} P$ value of terms ranged from 0.028 to 0.049 . All other $P$ values were less than 0.008 .

\section{Patterns associated with invasibility terms}

In contrast to propagule terms, the trends in associations with invasibility terms shared between invasion measures were much less consistent, excluding some notable exceptions. Human-caused forest fragmentation was positively associated with both invasion measures in the East, and positively associated with invasion richness in the West (Table 2; Fig. 2). In the East, natural forest fragmentation was negatively associated with both invasion measures (Table 2a; Fig. 2). In the 


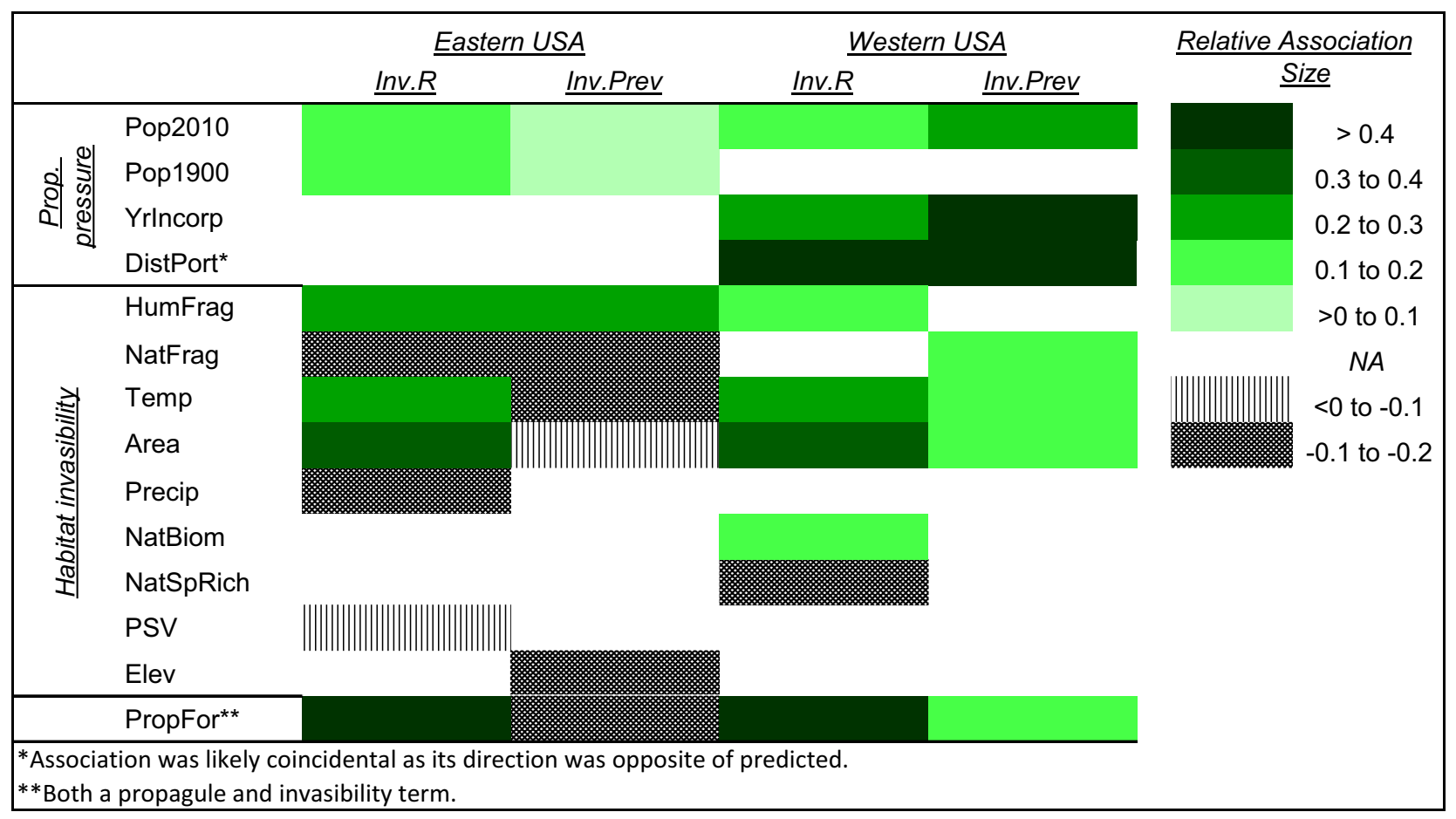

Figure 2 Comparisons of directions and relative sizes for associations with propagule and invasibility terms between both invasion richness (Inv.R) and invasion prevalence (Inv.Prev) for forests of the eastern and western USA. Note that both invasion measures share positive associations with the same propagule term within each region, whereas the associations with habitat invasibility terms are generally much less consistent. For actual slope $( \pm \mathrm{SE})$ estimates and statistical significance of model terms, see Table 2 . Abbreviations are defined in Table 1.

West, both county area and temperature shared positive associations with both invasion measures (Table 2b; Fig. 2).

The remaining associations were much less consistent. In eastern forests, temperature was positively and negatively associated with invasion richness and prevalence, respectively (Table 2a; Fig. 2); and native tree phylogenetic species variability (PSV) was weakly and negatively associated with invasion prevalence, but not invasion richness (Table 2a; Fig. 2). In the West, invasion richness, but not prevalence, was positively and negatively associated with native tree biomass and species richness, respectively (Table $2 \mathrm{~b}$; Fig. 2), and invasion prevalence, but not invasion richness, was positively associated with natural fragmentation (Table 2b; Fig. 2).

We found no evidence that the variability (i.e. $\mathrm{CV}$ ) in native tree live biomass, species richness or PSV was associated with either invasion measure in either the East or the West $(P=0.07$ to $0.94 ; \Delta \mathrm{AIC} \leq 1.31$ ), and the proportion of agricultural and developed area in a given county were not selected in final models (Appendix S7).

\section{DISCUSSION}

Our investigation provides insight into subcontinental invasion patterns and processes, confirming the utility of accounting for multiple invasion measures and subregional heterogeneity. We found that eastern forests were more heavily invaded than western forests, despite the existence of a few areas in the East where both invasion measures remain low. While some western forests have just as many invasive plant species as eastern forests, these areas were considerably smaller. Model pseudo $R^{2}$ values and the small $z$-scores for most model residuals revealed the appropriateness of our statistical models for our study regions and our study objectives. These models suggest that both propagule pressure and habitat invasibility contribute to macroscale patterns of forest plant invasions. Factors related to propagule pressure, however, contributed much more to these overall invasion patterns in western than eastern forests. Variability in sampling protocols among FIA regions seemed to affect our findings very little, as evidenced by the near absence of invasion patterns coinciding with FIA regional boundaries (Fig. 1a,b). Exceptions to this pattern are discussed below, as is the potential for variable sampling efforts among counties to affect our findings. Three broader insights into macroscale invasion patterns also emerged.

\section{1) The need to consider multiple invasion measures}

Invasion richness and prevalence exhibited variability in both spatial patterns and drivers. Not considering these differences could result in inaccurate conclusions. For example, the low-invasion richness found in parts of the upper Midwest may have led to the conclusion of a low degree of invasion. The high invasion prevalence of this region, however, reveals 
otherwise - the likely presence of a few common/dominant invaders - a well-supported pattern for this region [e.g. dense thickets of invasive the shrubs Rhamnus cathartica and Lonicera spp. are common throughout this region's forests (Hutchinson \& Vankat, 1997; Kurylo et al., 2007)]. Similarly, based on invasion richness, one might conclude some western forests to be equally invaded as eastern forests. The low-invasion prevalence found throughout the West, however, reveals invaders to be much less common. Nevertheless, the high invasion richness in these areas suggests these areas to be recipients of more propagules and therefore vulnerable to eventual high prevalence by shear probability (Williamson \& Fitter, 1996). Finally, the spatial disagreement between invasion measures revealed the need to better understand patterns and processes related to measures of diversity other than invasion richness, for example beta and gamma diversity (Whittaker, 1960).

\section{2) Declining effects of propagule pressure}

Our analyses, by accounting for spatial heterogeneity, also detected a declining effect over time of propagule pressure on macroscale invasion patterns. Propagule terms were relatively unimportant in statistical models for eastern forests despite these forests being heavily invaded; the opposite was true for western forests. These results are historically reasonable. The states to which eastern counties belong were incorporated into the USA, on average, 70 years earlier than the states of western counties (Iannone et al., present study); thus, their forests have experienced longer periods of human-induced propagule pressure. Longer periods of propagule pressure likely explain the greater degree of spatial agreement between invasion measures found in the East than in the West, given the positive effects over time of propagule pressure on both establishment and abundance (Lockwood et al., 2005). This evidence suggests that, in the near future, the arrival of new propagules will affect macroscale invasion patterns to a much greater extent in western than in eastern forests. The fact that terms reflective of human legacy (i.e. population in 1900 and years since incorporation into the USA) were as much as six times more strongly associated with invasion measures in western than in eastern forests further supports this hypothesis. It is, however, likely that propagule pressure will influence more localized invasion patterns in eastern forests, especially in remaining low-invasion pockets.

The association trends displayed by two of the propagule terms warrant mention. First, although proportion of forest was associated with both invasion measures in eastern and western forests, it is difficult to interpret these associations, as this term reflects both propagule pressure and habitat invasibility (Table 1). Furthermore, as the number of plots monitored within each county varied relative to the forested area within each county (Bechtold \& Patterson, 2005), the positive associations detected between this term and invasion richness may reflect sampling bias (Patiño et al., 2014). Nevertheless, our analysis still detected many other potential contributors to patterns of invasion richness. Second, the positive associations between distance to the nearest port and both invasion measures in the West were likely coincidental. These associations would be expected to be negative if this variable contributed to forest plant invasions. Moreover, alternative findings may have arisen had we investigated the distance to the top ten nearest ports in the western USA, rather than in the entire USA, or other ports of propagule entry such as airports (McCullough et al., 2006; Hulme, 2009).

\section{3) Drivers of differences between spatial patterns of invasion measures are stage specific}

Various conceptual models of invasion acknowledge different stages ranging from introduction and establishment to spread and impact (e.g. Catford et al., 2009). Our analyses suggest that eastern and western forests as a whole are at different stages of invasion and that the drivers of differences between the macroscale spatial patterns of invasion richness and prevalence change across these stages. The low-invasion prevalence throughout the West suggests these forests to be collectively in early invasion stages, that is establishment and spread. The facts that propagule terms were strongly associated with both invasion measures in this region and that invasion richness was high in some areas, but invasion prevalence remained low throughout, suggest that spatial variability in propagule inputs accompanied by a lag between these propagules establishing and becoming common (Crooks, 2005) drives this difference. The fact that propagule pressure increases the establishment and abundance of most species supports this hypothesis (Lockwood et al., 2005).

In contrast, both invasion richness and prevalence were high throughout much of the East, suggesting these forests to collectively be in late invasion stages. While spatial patterns of invasion richness and prevalence were similar in this region, differences still existed. Although not explicitly investigated, our analyses suggest cross-species variation in response to habitat invasibility drives these differences. After all, within this region, propagule pressure had little effect on invasion patterns, and there was little agreement between invasion measures as to with which invasibility terms they were associated and in the directionality of these associations. These inconsistencies pose the possibility of the following scenario: an environmental condition limits collective establishment and thus invasion richness. Yet, an invader that is able to establish under this condition becomes common, causing increased prevalence and therefore driving spatial disagreement between the two invasion measures.

\section{Implications for management and policy}

Our analyses underscore the need for considering spatial heterogeneity when prescribing invasive plant management and policy, with some specific recommendations. First, not all areas need the same level of protection. For example, forests having low-invasion prevalence in the East likely warrant prioritization over western forests for monitoring and 
control as they probably experience greater propagule pressure from nearby forests. Second, the best strategies for limiting invasions are likely region specific. For example, both the low-invasion prevalence and the relatively strong contribution of propagule terms to western invasion patterns suggest that policies within this region aimed at limiting propagule influx and movement could prevent new invasions. In contrast, as most eastern forests are already heavily invaded, efforts may be better spent on limiting propagule movement into specific low-invasion areas.

Comparing the directionality and magnitude of detected associations both between and within regions revealed that in order for policies to be effective they must be applied at appropriate geographic scales. For example, human population density in 2010 and human-caused forest fragmentation were both positively associated with invasions in eastern and western forests. This cross-regional consistency confirms the wide-ranging effects of human-induced stressors on invasion (Pyšek et al., 2010), and more importantly suggests that policies pertaining to these stressors aimed at limiting forest plant invasions can be implemented effectively at the national level. Policymakers must, however, consider the variability between regions in the strength of these associations and therefore the potential spatial heterogeneity in policy effectiveness. Thus, national-level policies need evaluation across multiple scales and regions.

In contrast, variables having different directionality of associations between regions and/or relatively weak associations within regions likely contribute to invasion patterns at smaller scales. Therefore, national-level policies pertaining to the effects of these factors on invasion will likely be ineffective. For example, we found natural forest fragmentation to be negatively associated with eastern invasions, but positively associated with western ones, suggesting geographic variability in how forest edges affect species movement (Murcia, 1995). As for weak within-region associations, we found a weak positive association between invasion richness and native tree biomass in western forests, suggesting mutually suitable growing conditions or increased vulnerability of more-productive, or later-successional, forests to invasion (Wardle, 2002; Martin et al., 2009). We also found weak negative associations between invasion richness and both native tree species richness in western forests and native tree phylogenetic species variability in eastern forests, suggesting biotic resistance (Levine et al., 2004). Nevertheless, the small sizes of all of these associations likely indicate localized processes.

\section{Future directions}

\section{Need for data improvement}

Despite the clear utility illustrated here and elsewhere of studying multiple invasion measures (Guo \& Symstad, 2008; Catford et al., 2012), acquiring these measures for large geographic areas is challenging. Even our dataset with its 2524 county-level estimates has its limitations. For example, estimates of invasion richness may be biased due to variability among counties in sampling efforts (Patiño et al., 2014). Future iterations of this dataset will likely benefit from controlling for this bias. Despite some of the variability among FIA regions in sampling protocols being ecologically meaningful (e.g. region-specific species monitoring lists), this variability may have had some minor effects on interpretation of invasion patterns (e.g. invasion patterns coinciding with the California-Nevada and Missouri-Arkansas borders; Fig. 1a,b). A standardized national protocol, by eliminating such bias, could improve our understanding of invasion patterns. Finally, other measures reflective of invasion dominance (e.g. biomass or cover) may be more useful to investigate, as they may better reflect invader impacts (Hillebrand et al., 2008).

\section{Need for greater analytical complexity}

Our analyses also confirmed the need for considering greater complexity when investigating macroscale invasions. Two levels of complexity are straightforward to address. First, our study accounted only for characteristics of invaded systems and invasion drivers. Improved understanding is likely from considering the third invasion component (sensu Catford et al., 2009) - invader traits - perhaps by modelling individual 'model' invaders possessing potentially important traits (e.g. Pyšek \& Richardson, 2007), using a framework similar to that used here. Determining which invasive species contribute to the patterns we observed may also help to address this complexity. Second, our investigation confirmed the utility of accounting for spatial heterogeneity by dividing large geographic areas into ecologically meaningful subsections. Had we not utilized this easily repeatable technique, we would not have detected declining effects of propagule pressure nor changes in what drives spatial differences between invasion measures.

Three other complexities are less straightforward to deal with. First, we found evidence of variables affecting invasions at different scales and thus the potential for cross-scale interactions. For example, our findings suggest that both humancaused forest fragmentation and population density facilitate invasion nationwide, while native tree diversity hinders invasion, but only in specific subregions. Second, we found evidence of nonlinear effects, as evidenced by the strength of the association between human-caused forest fragmentation and invasion varying nearly twofold between eastern and western forests. Third, we found the need to account for spatial autocorrelation. Our preliminary analyses, however, by revealing the most appropriate neighbourhood distance to be 1 degree, suggest the majority of spatial autocorrelation contributing to macroscale invasion patterns occurs at relatively small scales, that is within a few-county radius, a hypothesis supported by a recent study into patterns of exotic plant invasions having states as the sample unit (Guo et al., 2012). Of course closer inspection of individual variables is needed to determine those to which this pattern applies. 
Each of these complexities suggests the need to investigate invasions using a macrosystems framework (Heffernan et al., 2014). While methods already exits to address these complexities [e.g. hierarchical Bayesian and individual-based models (Levy et al., 2014)], the development of other methods will likely facilitate our understanding of how these complexities contribute to macroscale invasion patterns. Furthermore, investigations testing the efficacy of policy recommendations, including those presented here, should incorporate these complexities to ensure the development of the spatially heterogeneous management practices and policy likely needed to limit the spread and impact of future invasions.

\section{ACKNOWLEDGEMENTS}

Thanks to the many FIA workers who collected the data used in this study; to Beth Schultz, Andrew Gray and Chris Witt for assisting with data compilation; and to Jarrod Doucette and Johanna Desprez for GIS-related advice. Comments from three anonymous referees improved this manuscript. This research was supported by NSF Macrosystems Biology grant \# 1241932 and by a Research Joint Venture Agreement 13-JV-11330110-043 between the USDA Forest Service and North Carolina State University.

\section{REFERENCES}

Araújo, M.B. \& Rozenfeld, A. (2014) The geographic scaling of biotic interactions. Ecography, 37, 406-415.

Bechtold, W.A. \& Patterson, P.L. (2005) The enhanced forest inventory and analysis program - national sampling design and estimation procedures. General Technical Report SRS-80. U.S. Department of Agriculture, Forest Service, Southern Research Station, Asheville.

Bivand, R. (2014) spdep: Spatial dependence: weighting schemes, statistics, and models. R package version 0.5-74. http://CRAN.R-project.org/package=spdep.

Brown, J.H. (1999) Macroecology: progress and prospect. Oikos, 87, 3-14.

Burnham, K.P. \& Anderson, D.R. (2002) Model selection and multi-model inference: a practical information-theoretic approach, 2nd edn. Springer, New York.

Catford, J.A., Jansson, R. \& Nilsson, C. (2009) Reducing redundancy in invasion ecology by integrating hypotheses into a single theoretical framework. Diversity and Distributions, 15, 22-40.

Catford, J.A., Vesk, P.A., Richardson, D.M. \& Pyšek, P. (2012) Quantifying levels of biological invasion: towards the objective classification of invaded and invasible ecosystems. Global Change Biology, 18, 44-62.

Cleland, D.T., Avers, P.E., McNab, W.H., Jensen, M.E., Bailey, R.G., King, T. \& Russell, W.E. (1997) National hierarchical framework of ecological units. Ecosystem management applications for sustainable forest and wildlife resources (ed. by M.S. Boyce and A. Haney), pp. 181-200. Yale University Press, New Haven.

Cleland, D.T., Freeouf, J.A., Keys, J.E., Nowacki, G.J., Carpenter, C.A. \& McNab, W.H. (2007) Ecological subregions: sections and subsections for the conterminous United States. General Technical. Report WO-76. U.S. Department of Agriculture, Forest Service, Washington, DC. Map, presentation scale 1:3,500,000; Albers equal area projection; colored.

Crooks, J.A. (2005) Lag times and exotic species: the ecology and management of biological invasions in slow-motion. Ecoscience, 12, 316-329.

Diniz-Filho, J.A.F., Rangel, T.F.L.V.B. \& Bini, L.M. (2008) Model selection and information theory in geographical ecology. Global Ecology and Biogeography, 17, 479-488.

Fei, S., Phillips, J. \& Shouse, M. (2014) Biogeomorphic impacts of invasive species. Annual Review of Ecology, Evolution, and Systematics, 45, 69-87.

Gavier-Pizarro, G.I., Radeloff, V.C., Stewart, S.I., Huebner, C.D. \& Keuler, N.S. (2010) Housing is positively associated with invasive exotic plant species richness in New England, USA. Ecological Applications, 20, 1913-1925.

Gonzalez, P., Hasson, R., Lakyda, P., McCallum, I., Nilsson, S., Pulhin, J., van Rosenberg, B., Scholes, B., Shvidenko, A., Barber, C.V. \& Persson, R. (2005) Forest and woodland systems. Millennium ecosystem assessment: ecosystems and human well-being: current state \& trends assessment (ed. by R. Hassan, R. Scholes and N. Ash), pp. 585-621. Island Press, Washington.

Guo, Q. \& Symstad, A. (2008) A two-part measure of degree of invasion for cross-community comparisons. Conservation Biology, 22, 666-672.

Guo, Q., Rejmanek, M. \& Wen, J. (2012) Geographical, socioeconomic, and ecological determinants of exotic plant naturalization in the United States: insights and updates from improved data. NeoBiota, 12, 41-55.

Heffernan, J.B., Soranno, P.A., Angilletta, M.J., Buckley, L.B., Gruner, D.S., Keitt, T.H., Kellner, J.R., Kominoski, J.S., Rocha, A.V., Xiao, J., Harms, T.K., Goring, S.J., Koenig, L.E., McDowell, W.H., Powell, H., Richardson, A.D., Stow, C.A., Vargas, R. \& Weathers, K.C. (2014) Macrosystems ecology: understanding ecological patterns and processes at continental scales. Frontiers in Ecology and the Environment, 12, 5-14.

Helmus, M.R., Bland, T.J., Williams, C.K. \& Ives, A.R. (2007) Phylogenetic measures of biodiversity. The American Naturalist, 169, E68-E83.

Hillebrand, H., Bennett, D.M. \& Cadotte, M.W. (2008) Consequences of dominance: a review of evenness effects of local and regional ecosystem processes. Ecology, 89, 1510-1520.

Hulme, P.E. (2009) Trade, transport and trouble: managing invasive species pathways in an era of globalization. Journal of Applied Ecology, 46, 10-18.

Hulme, P.E., Pyšek, P., Jarošík, V., Pergl, J., Schaffner, U. \& Vilá, M. (2013) Bias and error in understanding plant 
invasion impacts. Trends in Ecology and Evolution, 28, 212-218.

Hutchinson, T.F. \& Vankat, J.L. (1997) Invasibility and effects of Amur honeysuckle in Southwestern Ohio forests. Conservation Biology, 11, 1117-1124.

Iannone, B.V. III \& Galatowitsch, S.M. (2008) Altering light and soil $\mathrm{N}$ to limit Phalaris arundinacea reinvasion in sedge meadow restorations. Restoration Ecology, 16, 689-701.

Iannone, B.V. III, Umek, L.G., Heneghan, L. \& Wise, D.H. (2013) Amending soil with mulched European buckthorn (Rhamnus cathartica) does not reduce reinvasion. Ecological Restoration, 31, 264-273.

Kennedy, T.A., Naeem, S., Howe, K.M., Knops, J.M.H., Tilman, D. \& Reich, P. (2002) Biodiversity as a barrier to ecological invasion. Nature, 417, 636-638.

Kissling, W.D. \& Carl, G. (2008) Spatial autocorrelation and the selection of simultaneous autoregressive models. Global Ecology and Biogeography, 17, 59-71.

Kurylo, J.S., Knight, K.S., Stewart, J.R. \& Endress, A.G. (2007) Rhamnus cathartica: native and naturalized distribution and habitat preferences. The Journal of the Torrey Botanical Society, 134, 420-430.

Legendre, P. \& Legendre, L. (2012) Numerical ecology, 3rd, English edn. Elsevier Science B.V, Amsterdam.

Levine, J.M., Adler, P.B. \& Yelenik, S.G. (2004) A metaanalysis of biotic resistance to exotic plant invasions. Ecology Letters, 7, 975-989.

Levy, O., Ball, B.A., Bond-Lamberty, B. et al. (2014) Approaches to advance scientific understanding of macrosystems ecology. Frontiers in Ecology and the Environment, 12, 15-23.

Liebhold, A.M., McCullough, D.G., Blackburn, L.M., Frankel, S.J., Von Holle, B. \& Aukema, J.E. (2013) A highly aggregated geographical distribution of forest pest invasions in the USA. Diversity and Distributions, 19, 1208-1216.

Lin, W., Cheng, X. \& Xu, R. (2011) Impact of different economic factors on biological invasions on the global scale. PLoS One, 6, e18797.

Lockwood, J.L., Cassey, P. \& Blackburn, T. (2005) The role of propagule pressure in explaining species invasions. Trends in Ecology and Evolution, 20, 223-228.

Martin, P.H., Canham, C.D. \& Marks, P.L. (2009) Why forests appear resistant to exotic plant invasions: intentional introductions, stand dynamics, and the role of shade tolerance. Frontiers in Ecology and the Environment, 7, 142-149.

McCullough, D., Work, T., Cavey, J., Liebhold, A. \& Marshall, D. (2006) Interceptions of nonindigenous plant pests at US ports of entry and border crossings over a 17-year period. Biological Invasions, 8, 611-630.

McNab, W.H., Cleland, D.T., Freeouf, J.A., Keys, J.E. Jr., Nowacki, G.J. \& Carpenter, C.A. (2007) Description of ecological subregions: sections of the conterminous United States [CD-ROM]. Gen. Tech. Report WO-76B. U.S. Department of Agriculture, Forest Service, Washington, DC.

Mehrhoff, L.J., Silander, J.A. Jr., Leicht, S.A., Mosher, E.S. \& Tabak, N.M. (2014) Invasive plant atlas of New England.
The University of Georgia - Center for Invasive Species and Ecosystem Health. URL:http://www.eddmaps.org/ ipane/ipanespecies/current_inv.htm.

Murcia, C. (1995) Edge effects in fragmented forests: implications for conservation. Trends in Ecology and Evolution, 10, 58-62.

Oswalt, C., Fei, S., Guo, Q., Iannone, B.V. III, Oswalt, S., Pijanowski, B. \& Potter, K. (2015) A subcontinental view of forest plant invasions using national inventory data. NeoBiota, 24, 49-54.

Patiño, J., Weigelt, P., Guilhaumon, F., Kreft, H., Triantis, K.A., Naranjo-Cigala, A., Sólymos, P. \& Vanderpoorten, A. (2014) Differences in species-area relationships among the major lineages of land plants: a macroecological perspective. Global Ecology and Biogeography, 23, 1275-1283.

Pauchard, A. \& Shea, K. (2006) Integrating the study of nonnative plant invasions across spatial scales. Biological Invasions, 8, 399-413.

Pejchar, L. \& Mooney, H.A. (2009) Invasive species, ecosystem services and human well-being. Trends in Ecology and Evolution, 24, 497-504.

Powell, K.I., Chase, J.M. \& Knight, T.M. (2013) Invasive plants have scale-dependent effects on diversity by altering species-area relationships. Science, 339, 316-318.

Pyšek, P. \& Richardson, D.M. (2007) Traits associated with invasiveness in alien plants: where do we stand? Biological invasions (ed. by W. Nentwig), pp. 97-125. Springer, Berlin, Heidelberg.

Pyšek, P., Jarošík, V., Hulme, P.E. et al. (2010) Disentangling the role of environmental and human pressures on biological invasions across Europe. Proceedings of the National Academy of Sciences USA, 107, 12157-12162.

R Core Team (2013) R: A language and environment for statistical computing. R Foundation for Statistical Computing, Vienna, Austria. http://www.R-project.org.

Rejmánek, M. (2003) The rich get richer - responses. Frontiers in Ecology and the Environment, 1, 122-123.

Ricciardi, A. (2007) Are modern biological invasions an unprecedented form of global change? Conservation Biology, 21, 329-336.

Richardson, D.M. (2004) Plant invasion ecology_dispatches from the front line. Diversity and Distributions, 10, 315-319.

Ries, P., Dix, M.E., Lelmini, M. \& Thomas, D. (2004) National strategy and implementation plan for invasive species management. FS-805. U.S. Department of Agriculture, Forest Service, Washington, DC.

Schielzeth, H. (2010) Simple means to improve the interpretability of regression coefficients. Methods in Ecology and Evolution, 1, 103-113.

Shea, K. \& Chesson, P. (2002) Community ecology theory as a framework for biological invasions. Trends in Ecology and Evolution, 17, 170-176.

Simberloff, D., Martin, J.-L., Genovesi, P., Maris, V., Wardle, D.A., Aronson, J., Courchamp, F., Galil, B., GarcíaBerthou, E., Pascal, M., Pyšek, P., Sousa, R., Tabacchi, E. \& Vilà, M. (2013) Impacts of biological invasions: what's 
what and the way forward. Trends in Ecology and Evolution, 28, 58-66.

Smith, B.W., Miles, P.D., Vissage, J.S. \& Pugh, S.A. (2002) Forest resources of the United States, 2002. A technical document supporting the USDA forest service 2005 update of the RPA assessment. U.S. Department of Agriculture, North Central Research Station, St. Paul.

Stohlgren, T.J., Barnett, D.T. \& Kartesz, J.T. (2003) The rich get richer: patterns of plant invasions in the United States. Frontiers in Ecology and the Environment, 1, 11-14.

Stohlgren, T., Barnett, D., Flather, C., Fuller, P., Peterjohn, B., Kartesz, J. \& Master, L. (2006) Species richness and patterns of invasion in plants, birds, and fishes in the United States. Biological Invasions, 8, 427-447.

Tiefelsdorf, M., Griffith, D.A. \& Boots, B. (1999) A variancestabilizing coding scheme for spatial link matrices. Environment and Planning, 31, 165-180.

Vitousek, P.M., Mooney, H.A., Lubchenco, J. \& Melillo, J.M. (1997) Human domination of Earth's ecosystems. Science, 277, 494-499.

Wardle, D.A. (2002) Communities and ecosystems: linking the aboveground and belowground components. Princeton University Press, Princeton and Oxford.

Whittaker, R.H. (1960) Vegetation of the Siskiyou Mountains, Oregon and California. Ecological Monographs, 30, 279-338.

Williamson, M. \& Fitter, A. (1996) The varying success of invaders. Ecology, 77, 1661-1666.

\section{SUPPORTING INFORMATION}

Additional Supporting Information may be found in the online version of this article:

Figure S1 Location of FIA Regions, i.e. the institutional areas among which invasive species sampling protocols varied.
Table S2 List of invasive plant species monitored, their growth form, and the FIA Region(s) in which they were monitored.

Appendix S3 Explanation of utility and data compilation for propagule and invasibility terms.

Table S4 Data transformations conducted prior to analyses.

Figure S5 Geographic patterns of invasibility and propagule terms associated with patterns of invasion richness and/or prevalence in the forests of the eastern USA.

Figure S6 Geographic patterns of invasibility and propagule terms associated with patterns of invasion richness and/or prevalence in the forests of the western USA.

Appendix S7 Detailed results of multitiered analysis, including description of associations found, but not retained, in earlier stages of procedure.

Figure S8 Mapped z-scores of model residuals.

\section{BIOSKETCH}

Basil V. lannone III is a postdoctoral researcher at Purdue University. He studies the causes and consequences biological invasion from the local- to the macroscale. He also studies the effects that land management and ecological restoration practices aimed at limiting invasions have on the composition and functionality of ecological communities. URL: http://web.ics.purdue.edu/ biannone.

B.I. and S.F conceptualized the article, B.I. and C.O. conducted analyses, and all authors contributed to the writing.

Editor: Bethany Bradley 